\title{
Article \\ A New GaN HEMT Small-Signal Model Considering Source via Effects for 5G Millimeter-Wave Power Amplifier Design
}

\author{
Jihoon Kim
}

check for updates

Citation: Kim, J. A New GaN HEMT Small-Signal Model Considering Source via Effects for $5 \mathrm{G}$ Millimeter-Wave Power Amplifier Design. Appl. Sci. 2021, 11, 9120. https://doi.org/10.3390/app11199120

Academic Editor: Ernesto Limiti

Received: 28 August 2021

Accepted: 28 September 2021

Published: 30 September 2021

Publisher's Note: MDPI stays neutral with regard to jurisdictional claims in published maps and institutional affiliations.

Copyright: (C) 2021 by the author. Licensee MDPI, Basel, Switzerland. This article is an open access article distributed under the terms and conditions of the Creative Commons Attribution (CC BY) license (https:/ / creativecommons.org/licenses/by/ $4.0 /)$.
Department of Electronics Engineering, Pai Chai University, Daejeon 35345, Korea; j7h7.kim@pcu.ac.kr; Tel.: +82-42-520-5595

Featured Application: 5G millimeter-wave GaN HEMT power amplifier design.

\begin{abstract}
A new gallium nitride (GaN) high electron mobile transistor (HEMT) small-signal model is proposed considering source via effects. In general, GaN HEMTs adopt a source via structure to reduce device degradation due to self-heating. In this paper, the modified drain-source capacitance $\left(C_{d s}\right)$ circuit considering the source via structure is proposed. GaN HEMTs fabricated using a commercial $0.15 \mu \mathrm{m}$ GaN HEMT process are measured with a $67 \mathrm{GHz}$ vector network analyzer (VNA). The fabricated device is an individual source via (ISV) type. As a result, it is difficult to predict the measured S12 in the conventional small-signal model equivalent circuit. This causes errors in maximum stable gain/maximum available gain (MSG/MAG) and stability factor (K), which are important for circuit design. This paper proposes a small-signal equivalent circuit that adds the drain-source inductance to the drain-source capacitance considering the source via structure. The proposed equivalent circuit better reproduces the measured S12 without compromising the accuracy of other S-parameters up to $67 \mathrm{GHz}$ and improves the accuracy of MSG/MAG and K. It is expected that the proposed model can be utilized in a large-signal model for 5G millimeter-wave GaN HEMT power amplifier design in the future.
\end{abstract}

Keywords: GaN HEMT; source via effect; 5G millimeter-wave; small-signal model; power amplifier

\section{Introduction}

Gallium nitride (GaN) semiconductors have a high breakdown voltage due to inherent wide-bandgap and high current density, which is advantageous for use as power semiconductors [1,2]. In addition, since the high electron mobility transistor (HEMT) structure has high electron mobility due to the generation of its unique 2-D electron gas (2-DEG), GaN HEMTs have been widely studied and utilized in high-frequency power amplifiers [3-7]. Since GaN HEMTs exhibit high power density but have a self-heating effect, a source via structure that can dissipate heat well to substrates is widely used in transistor layouts. As a result, accurate large-signal modeling reflecting the self-heating effect is essential [8-11]. Recently, with the commercialization of $5 \mathrm{G}$ communication, research on millimeter-wave power amplifiers using GaN HEMTs is being actively conducted [12-15]. Therefore, GaN HEMT large-signal modeling that reflects self-heating effects up to the millimeter-wave band is required. On the other hand, for accurate large-signal modeling, an accurate smallsignal model should be prioritized. In particular, as the operating frequency increases, a small-signal equivalent circuit that reflects the S-parameter according to the frequency well is required. Until now, many studies on GaN HEMT modeling have been successfully published [16-25]. Recently, some papers dealing with GaN HEMT small-signal modeling up to $110 \mathrm{GHz}$ have reported on millimeter-wave monolithic microwave integrated circuit (MMIC) design [22-25]. However, depending on the process, there was no consideration of the coupling effect that may appear with the source via process. This suggests that it may be necessary to modify the traditional HEMT small-signal equivalent circuit that has been 
used for millimeter-wave GaN HEMT small-signal modeling. In this paper, we propose a new GaN HEMT small-signal equivalent circuit considering the source via structure, usable at frequencies up to $67 \mathrm{GHz}$ including 5G communication frequencies. The structure of this paper is as follows: In Section 2, we propose a small-signal equivalent circuit reflecting the source via effect from the GaN HEMT structure to which an individual source via (ISV) is applied. Then, an extraction method and procedure of the proposed small-signal model are mentioned. Section 3 introduces the $67 \mathrm{GHz}$ S-parameter measurement setup conducted in this work and verifies the validity of the proposed model by comparing the conventional small-signal model and the proposed one with the measurement results. Finally, the conclusion follows.

\section{Materials and Methods}

\subsection{15 $\mathrm{mm}$ GaN HEMT ISV Structure and Source via Effect}

Due to high output power of several watts generated from a GaN HEMT device with a size of hundreds of micrometers, heat is inevitably generated from the device itself. The self-heating effect is a phenomenon in which device characteristics deteriorate due to temperature rise caused by power consumption in the device. In order to minimize this degradation, it is important to have a device layout that can dissipate heat well. An ISV structure in which heat is dissipated through multiple grounds by placing a backside ground via per source finger is widely used [26]. Figure 1 shows the ISV layout structure of a commercial GaN HEMT having a gate length of $0.15 \mu \mathrm{m}$ and a gate width of $4 \times 50 \mu \mathrm{m}$. As shown in Figure 1b, the heat generated by the device is dissipated to the ground through the backside vias connected to each source.

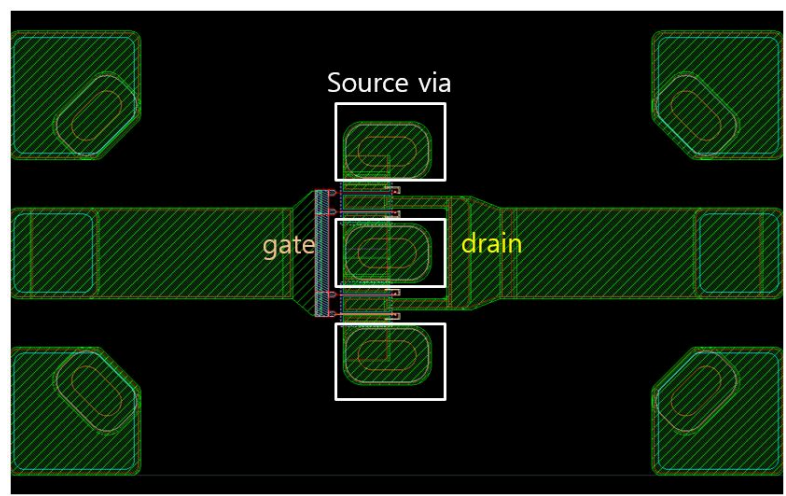

(a)

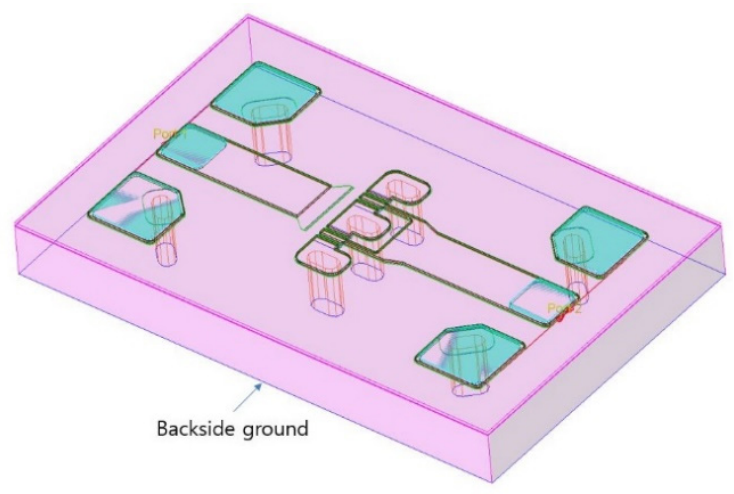

(b)

Figure 1. (a) Test pattern layout; (b) $3 \mathrm{D}$ view of $0.15 \times 4 \times 50 \mu \mathrm{m}$ GaN HEMT ISV.

The size of the backside via used in this process is about $60 \times 90 \mathrm{um}$, and the height is about $100 \mathrm{um}$. Due to this source via structure, the conventional small-signal equivalent circuit also needs to be modified. In particular, parasitics related to the source via structure, which have not been considered in the past, may have a non-negligible effect at the frequencies of the millimeter-wave band above $30 \mathrm{GHz}$. In this work, the parasitic effect due to the coupling between drain and source feeding lines surrounding the source via structure is mainly investigated. Figure 2 shows an enlarged GaN HEMT layout around the source via structure and an equivalent circuit representing it. Parasitic components that are actually generated are more complex but are simplified for convenience. It is true that additional proof is needed to clarify the exact physical phenomenon of the proposed equivalent circuit, but the possible physical structure is inferred from the more accurate equivalent circuit found empirically. At high frequencies, parasitic inductance and via resistance and inductance may be generated for a long path among multiple paths generated, while signals are coupled and passed in various directions of the source via from the drain feeding line. As shown in Figure 2, these are modeled by $C_{d s 1}, L_{d s}, R_{s}$, 
and $\mathrm{L}_{\mathrm{s}}$. Some paths may be short and there may be coupling signals that drop directly to ground. This is modeled by $\mathrm{C}_{\mathrm{ds} 2}$. More detailed verification of this will be carried out in a follow-up study.

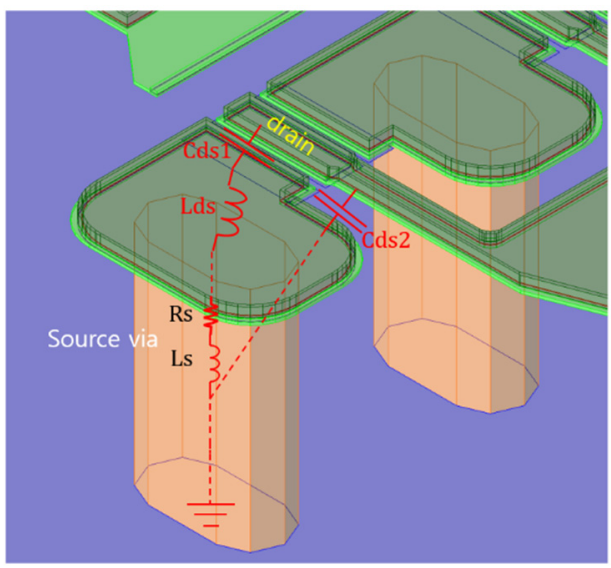

Figure 2. Enlarged source via structure of a GaN HEMT with its equivalent circuit.

To confirm this, 2.5 dimensional electromagnetic (EM) simulation is performed on the drain-source layout of the GaN HEMT device using ADS momentum software. Figure $3 a, b$ shows the EM layout and simulation results of the simplified one-port drain-source via structure. In particular, EM analysis is performed up to $120 \mathrm{GHz}$ to confirm the inductance effect. The layout shown in Figure 3a is mostly composed of metal layers, so the resistance of the metal itself is very small. Since the GaN HEMT substrate has a semi-insulated structure similar to that of GaAs, the substrate loss is also small. Therefore, the EM simulation result shows almost no loss.

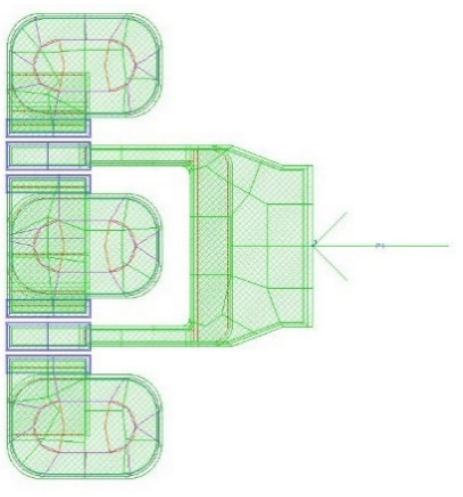

(a)

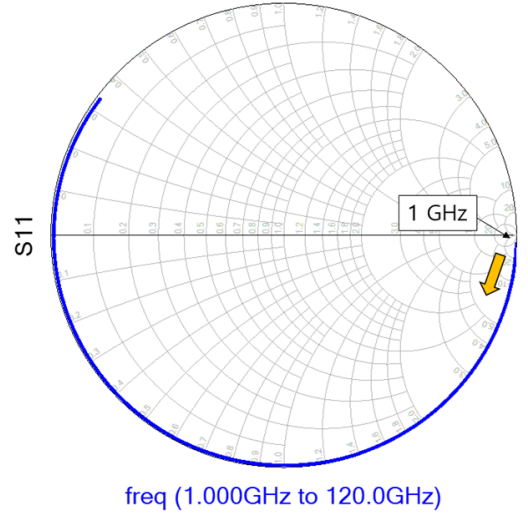

(b)

Figure 3. (a) EM layout and (b) simulation result of the simplified one-port drain-source via structure.

The change in phase from $-180^{\circ}$ to $+180^{\circ}$ also occurs when a capacitive component changes to an inductive component. When looking at the Smith chart, the point going from the lower semicircle to the upper semicircle is the instantaneous transition point. From the simulation result shown on the Smith chart in Figure 3b, it can be confirmed that parasitic inductance exists in the coupling components between the drain and source feeding lines.

Figure 4 shows the comparison of the S11 EM data obtained above with the simulation according to the equivalent circuit. Up to $30 \mathrm{GHz}$, there is no significant difference even when modeling the coupling phenomenon of the drain and source feeding lines as a shunt parasitic capacitor alone, but at $30 \mathrm{GHz}$ or more, there is a difference, and it can be seen that the equivalent circuit, including a parasitic inductor, reproduces the EM data more accurately. 


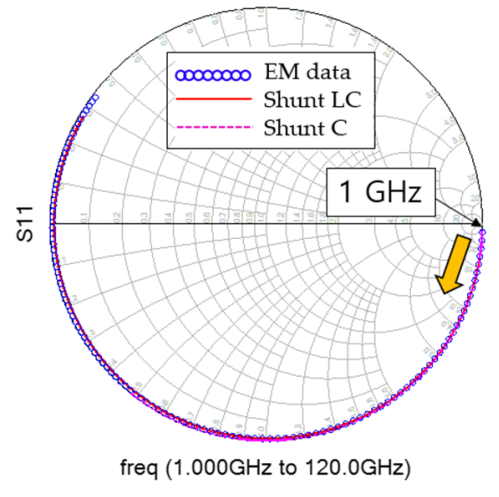

(a)

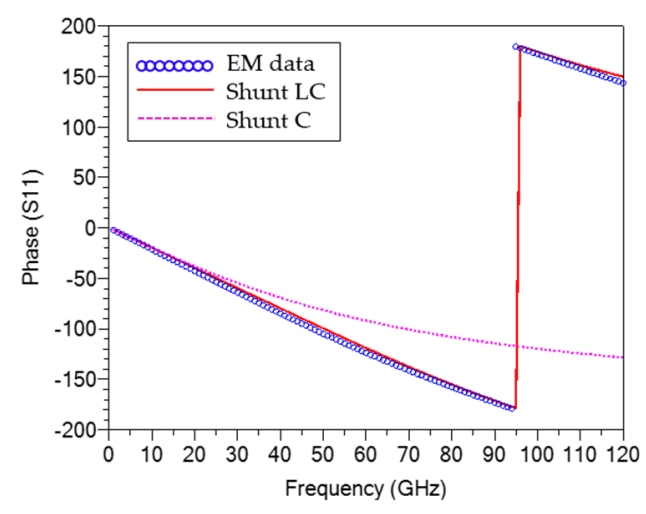

(b)

Figure 4. Comparison of S11 (a) on the Smith chart and (b) on the phase between EM data and equivalent circuits.

\subsection{New GaN HEMT Small-Signal Equivalent Circuit Considering Source via Effects}

The well-known small-signal equivalent circuit of III-V-based HEMTs including GaN HEMTs is shown in Figure 5a. For better understanding, the port numbers are also indicated when measuring S-parameters. The source port is usually connected to ground. It consists of a pad model composed of pad parasitic capacitances $\left(C_{p g}, C_{p d}\right)$ and pad parasitic inductances $\left(\mathrm{L}_{\mathrm{pg}}, \mathrm{L}_{\mathrm{pd}}\right)$, an extrinsic part depending on the layout structure, and an intrinsic part whose value changes according to the channel variation of the transistor by applied biases [27-29]. Usually, the $C_{\mathrm{ds}}$ is classified as an intrinsic model parameter, but empirically, the difference in values extracted according to biases is not large, so in some cases it is set as a constant [27-29]. In this work, it is assumed that both the extrinsic part and the intrinsic part of $C_{\mathrm{ds}}$ exist.

Figure $5 \mathrm{~b}$ shows the modified small-signal equivalent circuit including the source via effect discussed in the previous section. As shown in Figure $5 b$, the " $C_{d s}$ " part is modified to reflect the coupling effect between the drain and source via feeding lines. For convenience, we divide the $\mathrm{C}_{\mathrm{ds}}$ into $\mathrm{C}_{\mathrm{ds} 1}$ and $\mathrm{C}_{\mathrm{ds} 2}$, one including the source via inductance indicating that the coupling signal path is long and the other part directly falling to the ground, and the intrinsic $C_{d s}$ will be included in the latter.

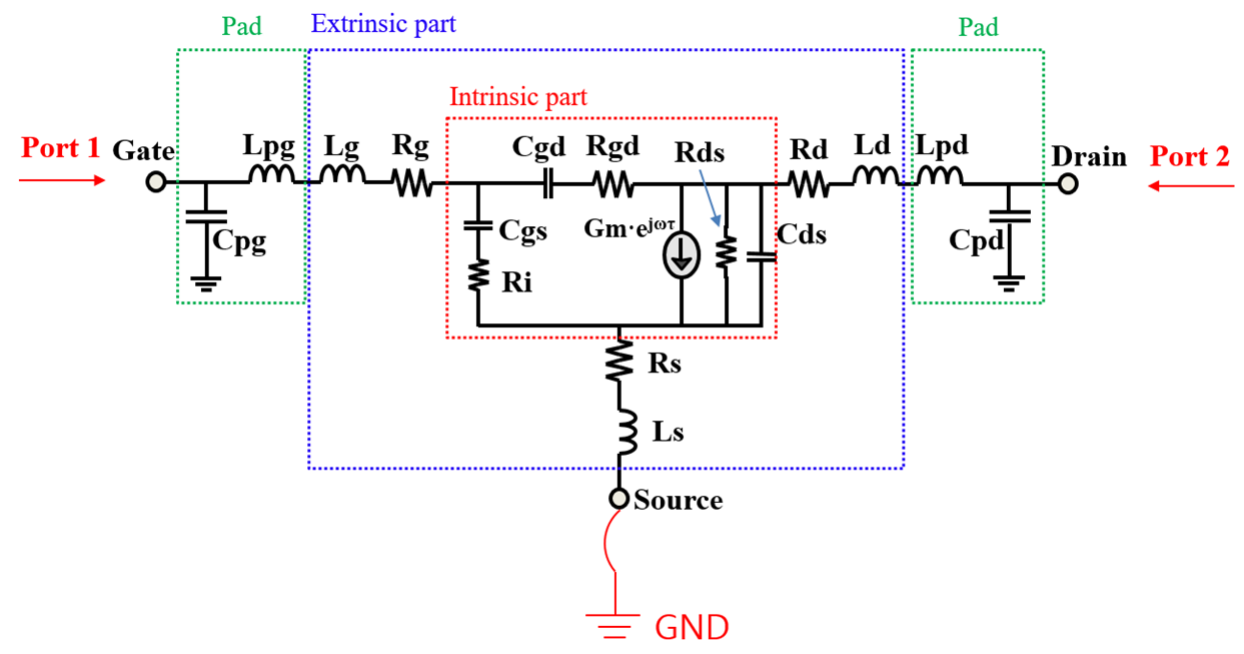

(a)

Figure 5. Cont. 


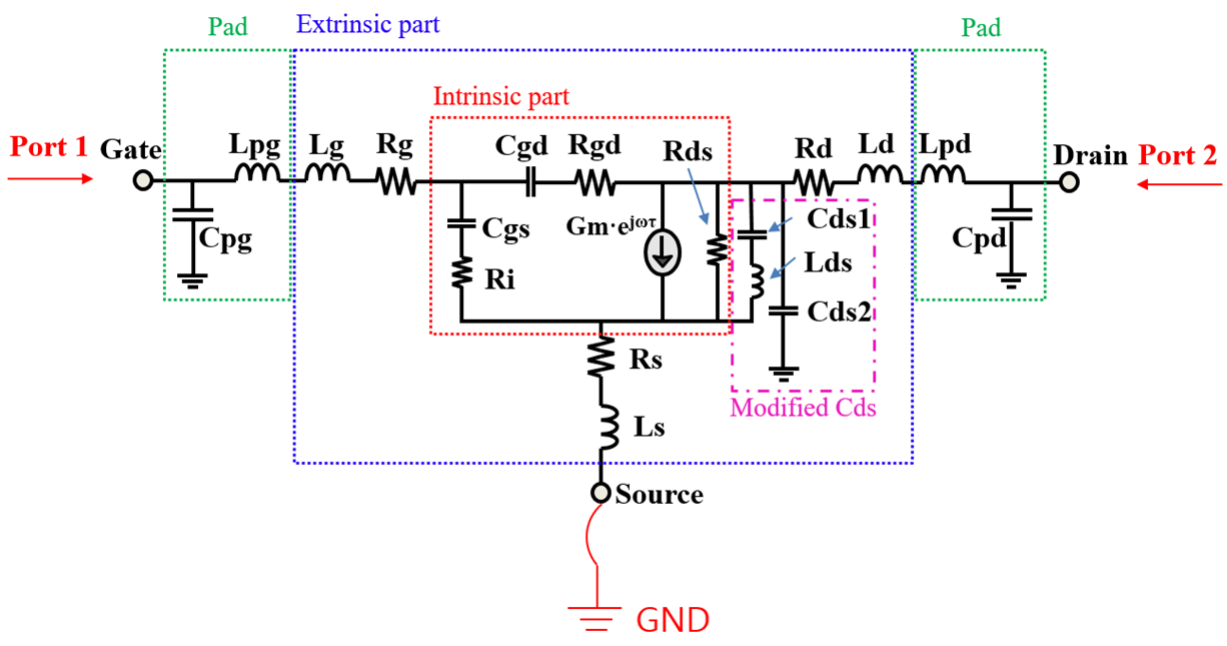

(b)

Figure 5. (a) Conventional and (b) proposed small-signal equivalent circuit of a GaN HEMT.

\subsection{Small-Signal Extraction Procedure Partially Assisted by EM Simulation}

In order to extract the model parameters of the modified small-signal equivalent circuit proposed in the previous section, the conventional extraction method is used along with the EM-based extraction method.

The first step is to extract the model parameters of the conventional small-signal equivalent circuit $[28,29]$. First, pad model parameters can be extracted through measuring the pad test pattern. After de-embedding the pad model, extrinsic model parameters can be extracted through S-parameters measured in the cold bias region where the drain-source voltage $\left(V_{\mathrm{ds}}\right)$ is $0 \mathrm{~V}$. Figure 6 shows the small-signal equivalent circuit in the cold bias region.

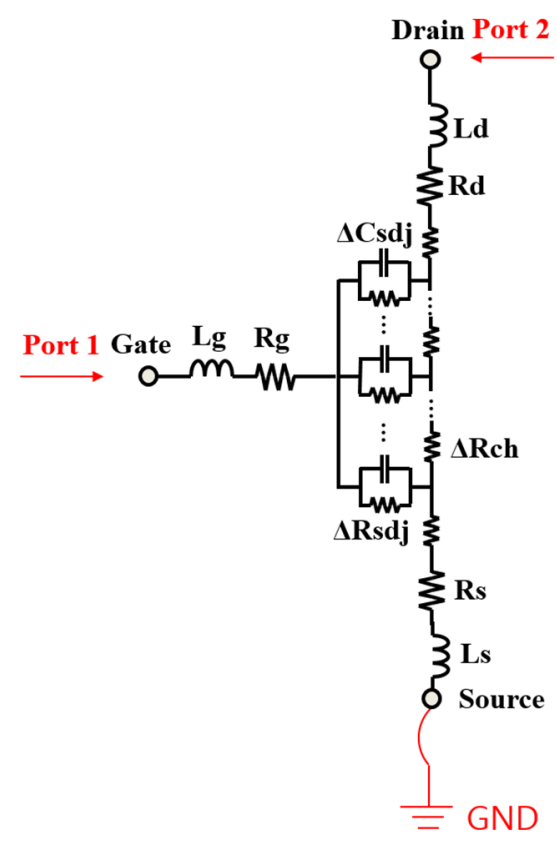

Figure 6. Schematic of GaN HEMT small-signal equivalent circuit in the cold bias region.

From the equivalent circuit of Figure 6, the Z parameters can be expressed as follows:

$$
Z_{11}=R_{s}+R_{g}+\frac{R_{c h}}{3}+R_{s d j} / / \frac{1}{j \omega C_{s d j}}+j \omega\left(L_{s}+L_{g}\right)
$$




$$
\begin{gathered}
Z_{12}=Z_{21}=R_{s}+\frac{R_{c h}}{2}+j \omega L_{s} \\
Z_{22}=R_{s}+R_{d}+R_{c h}+j \omega\left(L_{s}+L_{d}\right)
\end{gathered}
$$

where $R_{s}, R_{g}, R_{c h}$, and $R_{d}$ are the source, gate, channel, and drain resistance, respectively, $\mathrm{L}_{\mathrm{s}}, \mathrm{Lg}_{\mathrm{g}}$, and $\mathrm{L}_{\mathrm{d}}$ are the extrinsic source, gate, and drain inductance, respectively. $\mathrm{R}_{\mathrm{sdj}}$ and $\mathrm{C}_{\mathrm{sdj}}$ are the Schottky diode resistance and capacitance, respectively, and $\omega$ is the angular frequency. Charges in the depletion region vary according to the gate bias, and as the charge increases, the channel resistance decreases. Using this relation, $R_{S}+R_{d}$ can be extracted through the equation for the amount of charge and the real part of $Z_{22}$ according to the gate biases. Then, using the $R_{s}+R_{d}$ value obtained earlier, $R_{c h}$ at a specific bias can be found from the real part of $Z_{22}$ of Equation (3), and $R_{s}$ can be extracted from the real part of $Z_{12}$ of Equation (2). When $R_{s}$ is found, $R_{d}$ can also be extracted from the $R_{s}+R_{d}$ value. $L_{s}$ and $L_{d}$ can be extracted using the imaginary parts of $Z_{12}$ and $Z_{22}$ in a similar manner. However, $R_{g}$ and $L_{g}$ cannot be extracted as simply as above due to $R_{\text {sdj }}$ and $C_{\text {sdj. }}$. By applying the method used in [29] as it is, $L_{g}$ and $R_{g}$ can be extracted by approximating $Z_{11}$ using the fact that $\frac{1}{j \omega C_{s d j}}$ becomes very small compared to $R_{s d j}$ at high frequencies above $35 \mathrm{GHz}$.

In Figure 5a, the Y-parameters of intrinsic parts that change according to the bias can be expressed by the following Equations (4)-(7).

$$
\begin{gathered}
y_{11}=\frac{\omega^{2} R_{i} C_{g s}^{2}}{1+\omega^{2} R_{i}^{2} C_{g s}^{2}}+\frac{\omega^{2} R_{g d} C_{g d}^{2}}{1+\omega^{2} R_{g d}^{2} C_{g d}^{2}}+j \omega\left(\frac{C_{g s}}{1+\omega^{2} R_{i}^{2} C_{g s}^{2}}+\frac{C_{g d}}{1+\omega^{2} R_{g d}^{2} C_{g d}^{2}}\right) \\
y_{12}=-\frac{\omega^{2} R_{g d} C_{g s} C_{g d}}{1+\omega^{2} R_{g d}^{2} C_{g d}^{2}}-j \omega\left(\frac{C_{g d}}{1+\omega^{2} R_{g d}^{2} C_{g d}^{2}}\right) \\
y_{12}=\frac{g_{m} e^{-j \omega \tau}}{1+j \omega R_{i} C_{g s}}-\frac{\omega^{2} R_{g d} C_{g s} C_{g d}}{1+\omega^{2} R_{g d}^{2} C_{g d}{ }^{2}}-j \omega\left(\frac{C_{g d}}{1+\omega^{2} R_{g d}^{2} C_{g d}{ }^{2}}\right) \\
y_{22}=\frac{1}{R_{d s}}+\frac{\omega^{2} R_{g d} C_{g d}{ }^{2}}{1+\omega^{2} R_{g d}^{2} C_{g d}^{2}}+j \omega\left(\frac{C_{g d}}{1+\omega^{2} R_{g d}^{2} C_{g d}{ }^{2}}+C_{d s}\right)
\end{gathered}
$$

where $R_{i}, R_{g d}$, and $R_{d s}$ are the input, gate-drain, and output resistance, respectively, and $C_{g s}, C_{g d}$, and $G_{m}$ are the gate-source, gate-drain capacitance, and transconductance, respectively. Intrinsic model parameters can be extracted for each bias using the above equations from the Y-parameters obtained by de-embedding the pad model and extrinsic part from the measured S-parameters.

The second step is to replace the existing $C_{d s}$ obtained in the first step with the "modified $\mathrm{C}_{\mathrm{ds}}$ " shown in Figure $5 \mathrm{~b}$. It can be obtained by deriving an analytic equation, but in this work, EM simulation is used in an intuitive way without using complex equations. Since the "modified $\mathrm{C}_{\mathrm{ds}}$ " reflecting the source via effect is due to the layout structure, parameter extraction is possible with EM simulation and does not depend on the bias. Figure 7 shows the top view of full EM simulation of a GaN HEMT using ADS Momentum software. To obtain more realistic results, the measured GaN HEMT layout is brought directly into the EM simulation setup. In the layout shown in Figure 7, the gate layer is visible, but in ADS momentum, there is a function that does not activate this layer in the EM simulation setup. Therefore, the effect of the gate layer can be easily excluded, and the simulation is performed so that only the drain-source layout effect is shown. Finally, the modified $C_{\mathrm{ds}}$ can be extracted from the EM simulation result between the drain and source terminals. 


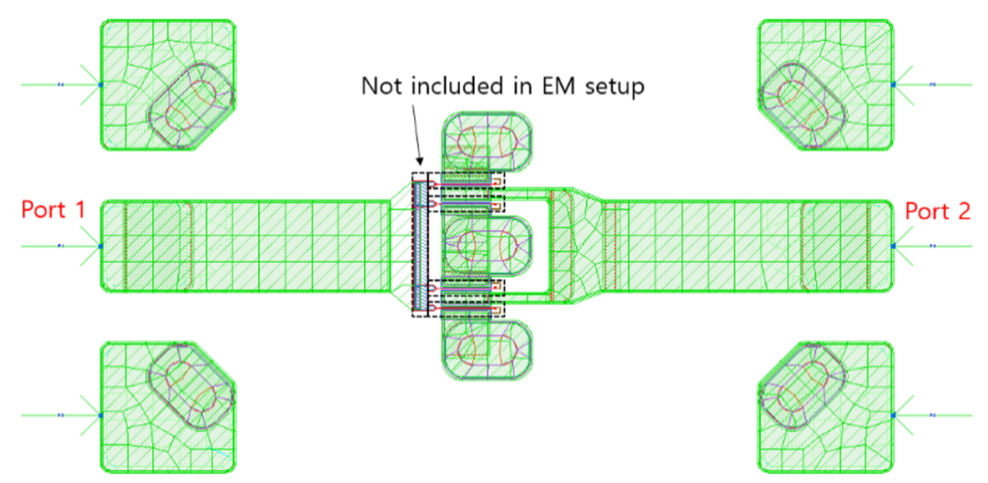

Figure 7. Top view of full EM simulation of a GaN HEMT using ADS momentum.

$\mathrm{C}_{\mathrm{ds} 1}, \mathrm{C}_{\mathrm{ds} 2}$, and $\mathrm{L}_{\mathrm{ds}}$ composing the "modified $\mathrm{C}_{\mathrm{ds}}$ " are extracted through fitting or optimization by comparing S22 obtained through EM simulation with the modeled S-parameter of the drain-source part extracted previously. The fitted $C_{\mathrm{ds} 2}$ does not yet contain an intrinsic part. Therefore, the intrinsic part can be added through the final comparison with the measured S-parameter, and the final small-signal model is completed through fine-tuning of each model parameter. Figure 8 is a block diagram showing the small-signal modeling procedure proposed in this work.

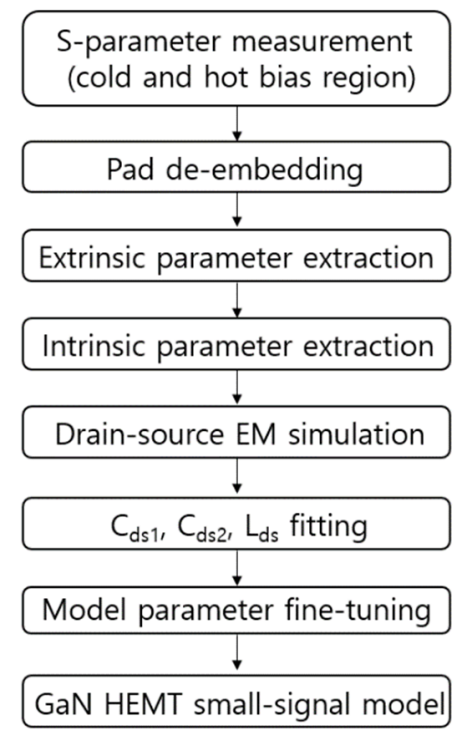

Figure 8. Block diagram of the proposed GaN small-signal modeling procedure.

\section{Measurement Setup and Results}

\section{1. $67 \mathrm{GHz}$ S-Parameter Measurement Set-Up}

A $67 \mathrm{GHz}$ S-parameter measurement setup was implemented to verify the new GaN HEMT small-signal model considering the source via effect proposed in Section 2. Figure 9 shows the block diagram of a $67 \mathrm{GHz}$ S-parameter measurement setup. Two-port RF signals come from a $67 \mathrm{GHz}$ vector network analyzer, and through on-wafer probing, the RF signals are input and output to a GaN HEMT device under test with dc biases through a dc source generator and two bias tees. This setup is connected to a PC through general purpose interface bus (GPIB) cables and automatically measures S-parameters according to biases and frequencies through IC-CAP software. In particular, since GaN HEMT devices have high operating voltage and high output power, it is necessary to carefully check the maximum input voltage and RF power allowed by the equipment and accessories. 


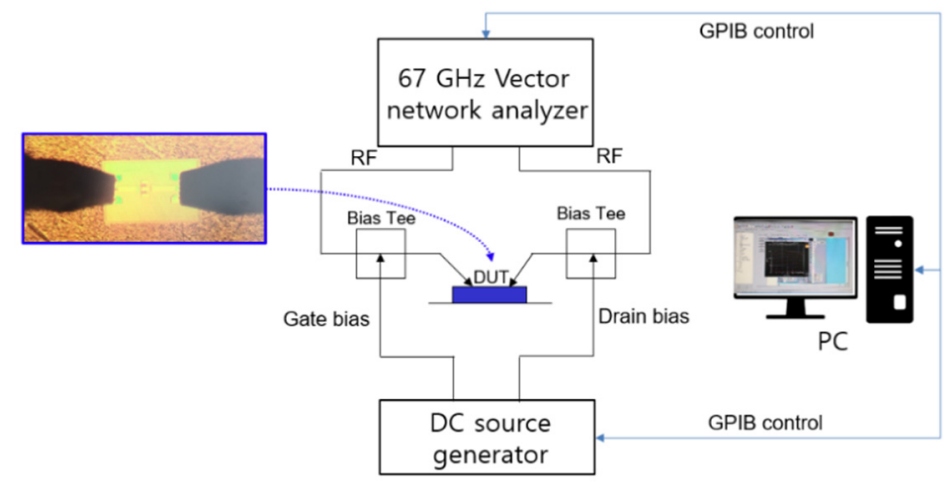

Figure 9. Block diagram of a $67 \mathrm{GHz}$ S-parameter measurement setup.

\subsection{Measurement Results}

The proposed small-signal modeling was performed on an ISV-type $4 \times 50 \mu \mathrm{m} \mathrm{GaN}$ HEMT fabricated using a commercial $0.15 \mu \mathrm{m}$ GaN HEMT process. First, the pad equivalent model parameters are extracted through the S-parameter measurement of the pad test pattern. The extracted values of $C_{p g}$ and $C_{p d}$ are both $18 \mathrm{fF}$, and those of $\mathrm{L}_{\mathrm{pg}}$ and $\mathrm{L}_{\mathrm{pd}}$ are both $30 \mathrm{pH}$. Next, S-parameters are measured from 0.2 to $67 \mathrm{GHz}$ in the cold and hot bias regions. The pinch-off voltage of the device is about $-2.8 \mathrm{~V}$, and the measurement bias region is a drain-source voltage of 0 to $28 \mathrm{~V}$ and a gate-source voltage $\left(\mathrm{V}_{\mathrm{gs}}\right)$ of -2.8 to $-0.8 \mathrm{~V}$. Table 1 shows the initial extrinsic and intrinsic parameters extracted using the conventional small-signal model parameter extraction method.

Table 1. Initially extracted extrinsic and intrinsic parameters of an ISV-type $4 \times 50 \mu \mathrm{m}$ GaN HEMT.

\begin{tabular}{|c|c|c|}
\hline Extrinsic/Intrinsic & Model Parameters & Extracted Value \\
\hline \multirow{6}{*}{ Extrinsic part } & $R_{g}$ & $0.67 \Omega$ \\
\hline & $\mathrm{R}_{\mathrm{S}}$ & $1.85 \Omega$ \\
\hline & $\mathrm{R}_{\mathrm{d}}$ & $0.1 \Omega$ \\
\hline & $\mathrm{Lg}_{\mathrm{g}}$ & $124.6 \mathrm{pH}$ \\
\hline & $\mathrm{L}_{\mathrm{s}}$ & $6.42 \mathrm{pH}$ \\
\hline & $\mathrm{L}_{\mathrm{d}}$ & $88.6 \mathrm{pH}$ \\
\hline \multirow{8}{*}{$\begin{array}{c}\text { Intrinsic part } \\
\left(\mathrm{V}_{\mathrm{ds}}=28 \mathrm{~V}, \mathrm{~V}_{\mathrm{gs}}=-1.6 \mathrm{~V}\right)\end{array}$} & $\mathrm{C}_{\mathrm{gs}}$ & $479 \mathrm{fF}$ \\
\hline & $\mathrm{R}_{\mathrm{i}}$ & $0.33 \Omega$ \\
\hline & $\mathrm{C}_{\mathrm{gd}}$ & $18.8 \mathrm{fF}$ \\
\hline & $\mathrm{R}_{\mathrm{gd}}$ & $354.5 \Omega$ \\
\hline & $\mathrm{G}_{\mathrm{m}}$ & $90.9 \mathrm{mS}$ \\
\hline & $\tau$ & $1.63 \mathrm{pS}$ \\
\hline & $\mathrm{R}_{\mathrm{ds}}$ & $900.9 \Omega$ \\
\hline & $\mathrm{C}_{\mathrm{ds}}$ & $138 \mathrm{fF}$ \\
\hline
\end{tabular}

Next, to replace the $C_{d s}$ obtained above with the "modified $C_{d s}$ " shown in Figure $5 b$, EM simulation is used as shown in Figure 7. Based on the EM simulation result, the values of $\mathrm{C}_{\mathrm{ds} 1}, \mathrm{~L}_{\mathrm{ds}}$, and $\mathrm{C}_{\mathrm{ds} 2}$ extracted by iterative fitting are $40 \mathrm{fF}, 40 \mathrm{pH}$, and $50 \mathrm{fF}$, respectively. Figure 10 shows the comparison of the S-parameter of the extracted "modified $\mathrm{C}_{\mathrm{ds}}$ " circuit with the EM simulated one. The "modified $C_{\mathrm{ds}}$ " circuit agrees better with the EM result than the conventional $C_{\mathrm{ds}}$. 


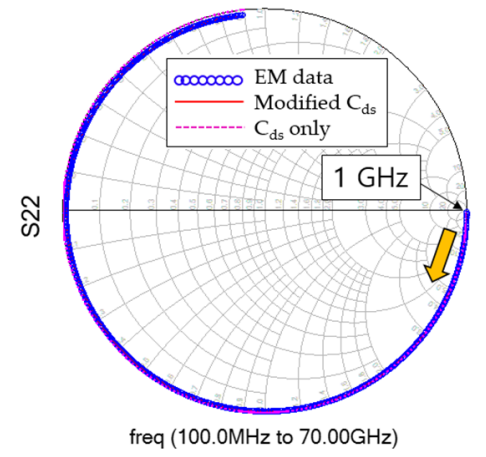

(a)

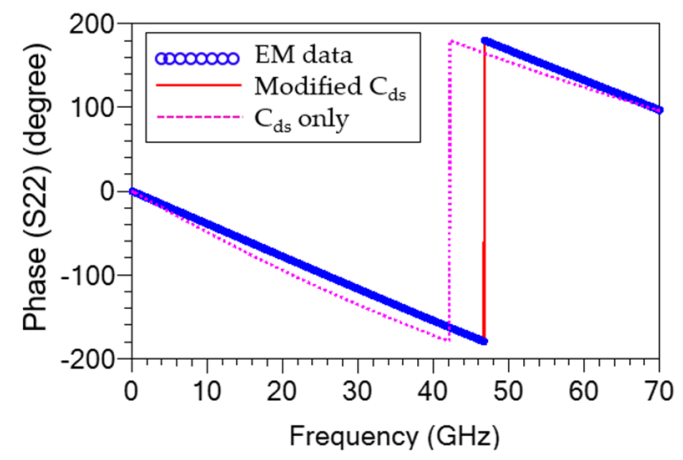

(b)

Figure 10. Comparison of the S-parameter of the extracted "modified $\mathrm{C}_{\mathrm{ds}}$ " circuit with the EM simulated one through (a) Smith chart and (b) phase.

Finally, the intrinsic part of $\mathrm{C}_{\mathrm{ds}}$, which is about $25 \mathrm{fF}$, can be added through the final comparison with the measured S-parameter, and the complete small-signal model is optimized through fine-tuning of each model parameter.

To verify the validity of the small-signal model completed through the above procedure, the S-parameters of small-signal models and the measured S-parameters are compared from 0.2 to $67 \mathrm{GHz}$ with respect to several biases around the load line, which is important for power amplifier design. In addition, the stability factor (K) and MSG/MAG that can be calculated from the S-parameter results are also compared. The formulas can be expressed as follows [30]:

$$
\begin{gathered}
\mathrm{K}=\frac{\left(1-|S 11|^{2}-|S 22|^{2}+|S 11 \cdot S 22-S 12 \cdot S 21|^{2}\right)}{(2 \cdot|S 12 \cdot S 21|)} \\
\text { MAG }=\frac{\left|S_{21}\right|}{\left|S_{12}\right|}\left(K-\sqrt{K^{2}-1}\right)(K>1) \\
\text { MSG }=\frac{\left|S_{21}\right|}{\left|S_{12}\right|}(\mathrm{K}<1)
\end{gathered}
$$

Figures 11-13 show the comparison of S-parameters, MSG/MAG, and K under some biases according to the load line.

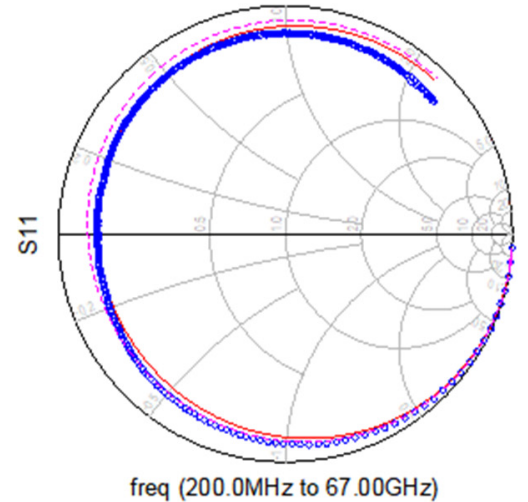

(a)

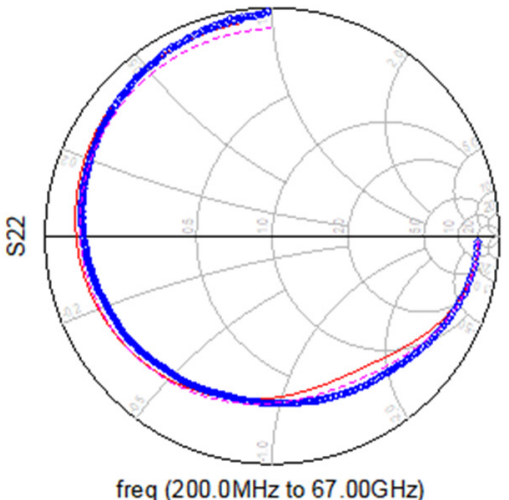

(b)

Figure 11. Cont. 


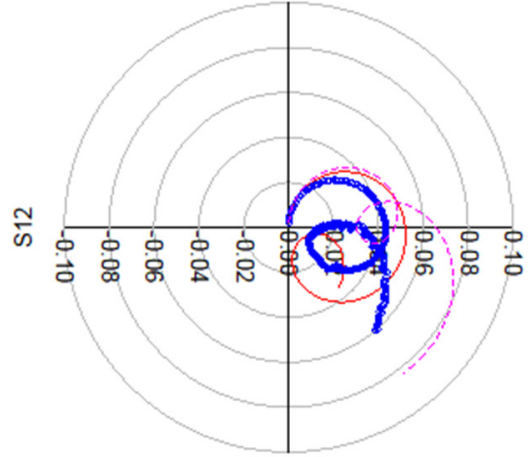

freq $(200.0 \mathrm{MHz}$ to $67.00 \mathrm{GHz})$

(c)

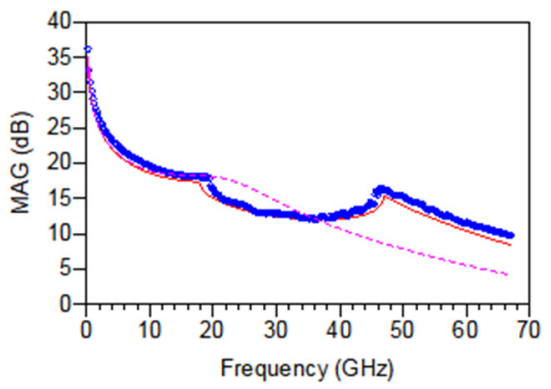

(e)

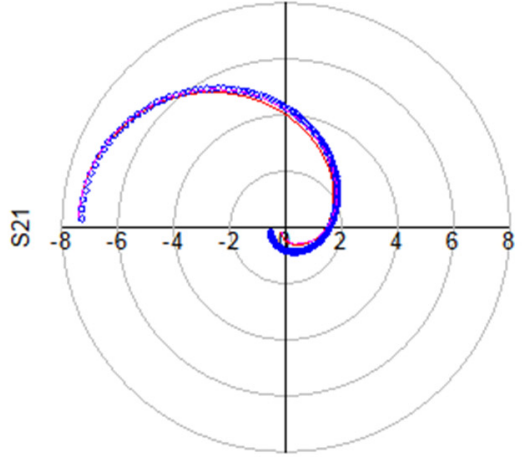

freq $(200.0 \mathrm{MHz}$ to $67.00 \mathrm{GHz})$

(d)

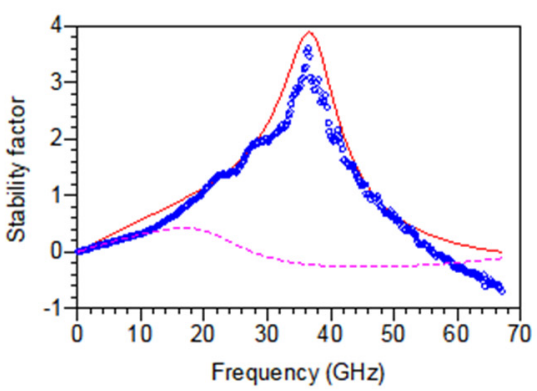

(f)

Figure 11. Comparison of (a) S11, (b) S22, (c) S12, (d) S22, (e) MSG/MAG, and (f) stability factor among the measurement (blue circle), the conventional model (pink dashed line), and the proposed model (red line) from 0.2 to $67 \mathrm{GHz}$ under $\mathrm{V}_{\mathrm{ds}}=28 \mathrm{~V}, \mathrm{~V}_{\mathrm{gs}}=-1.6 \mathrm{~V}$.

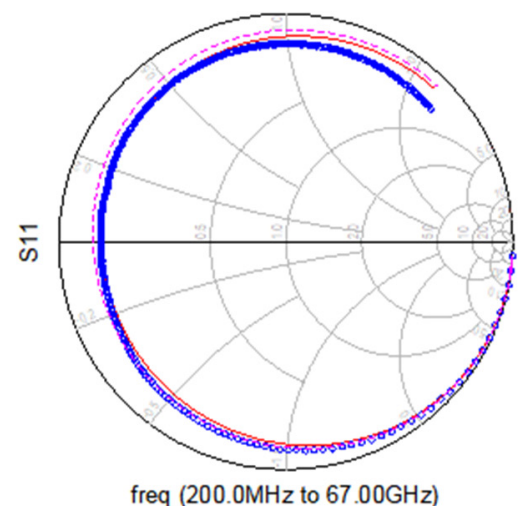

(a)

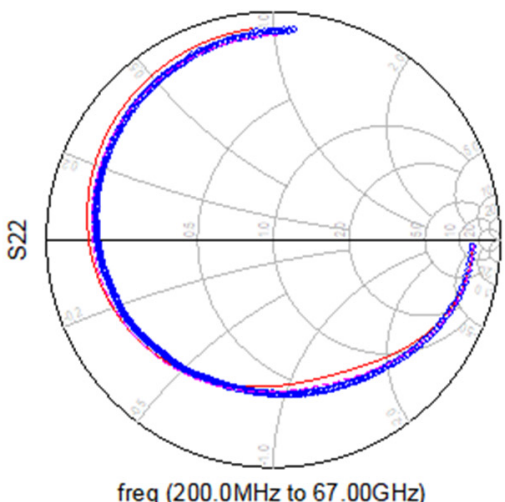

(b)

Figure 12. Cont. 


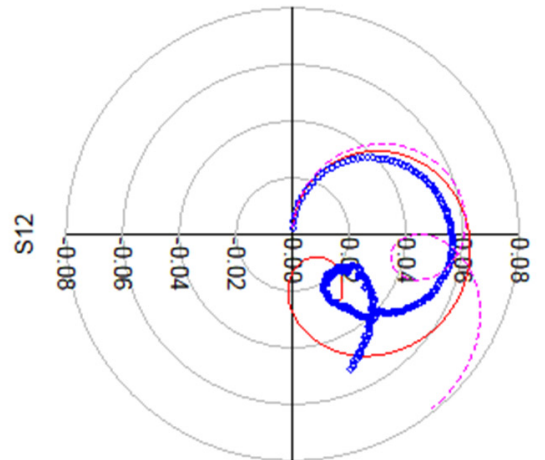

freq $(200.0 \mathrm{MHz}$ to $67.00 \mathrm{GHz})$

(c)

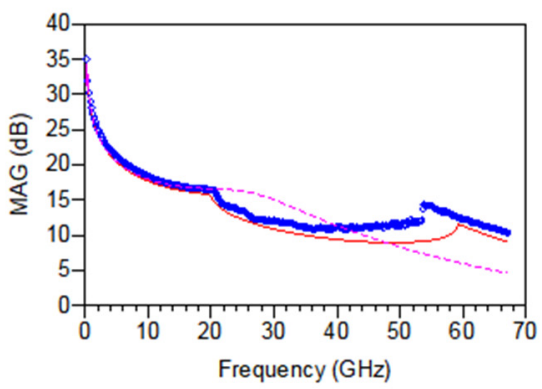

(e)

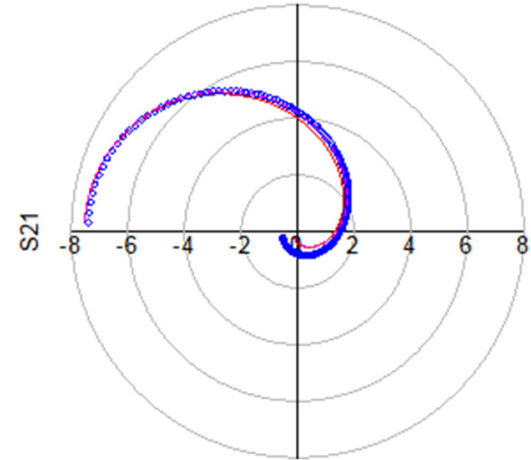

freq $(200.0 \mathrm{MHz}$ to $67.00 \mathrm{GHz})$

(d)

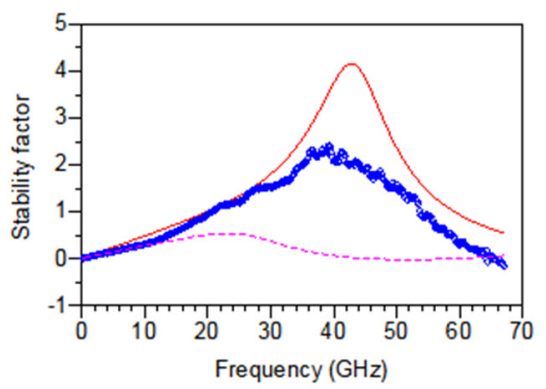

(f)

Figure 12. Comparison of (a) S11, (b) S22, (c) S12, (d) S22, (e) MSG/MAG, and (f) stability factor among the measurement (blue circle), the conventional model (pink dashed line), and the proposed model (red line) from 0.2 to $67 \mathrm{GHz}$ under $\mathrm{V}_{\mathrm{ds}}=20 \mathrm{~V}, \mathrm{~V}_{\mathrm{gs}}=-1.2 \mathrm{~V}$.

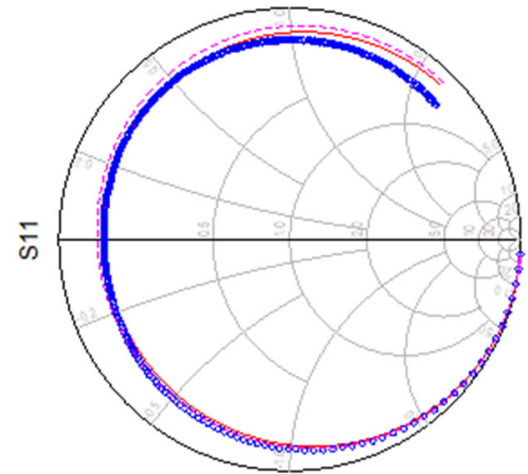

freq $(200.0 \mathrm{MHz}$ to $67.00 \mathrm{GHz})$

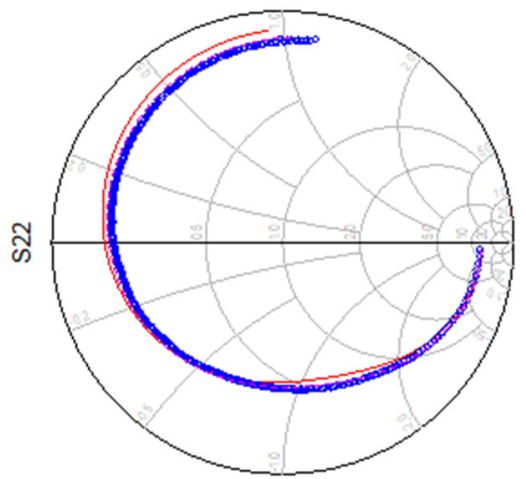

freq $(200.0 \mathrm{MHz}$ to $67.00 \mathrm{GHz})$

(a)

(b)

Figure 13. Cont. 


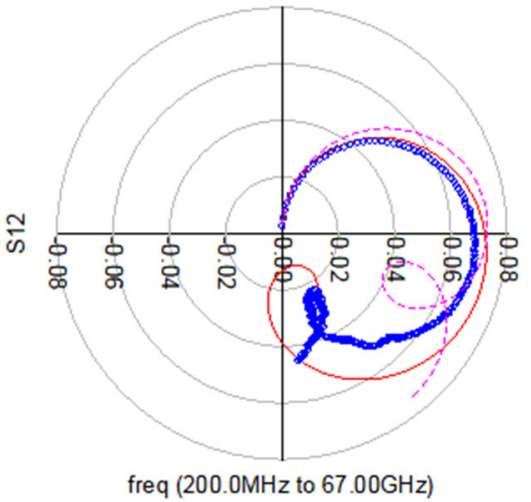

(c)

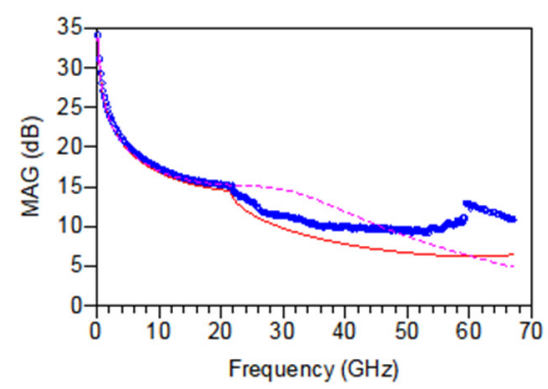

(e)

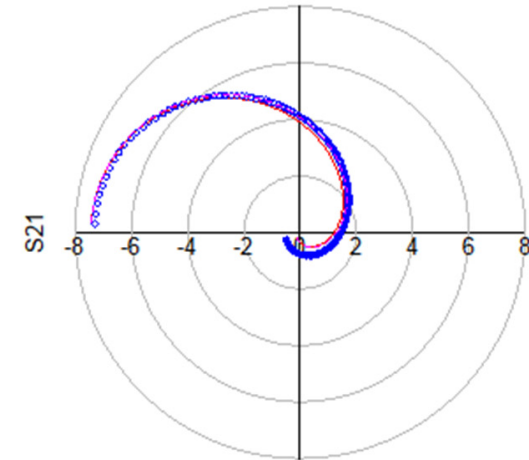

freq $(200.0 \mathrm{MHz}$ to $67.00 \mathrm{GHz})$

(d)

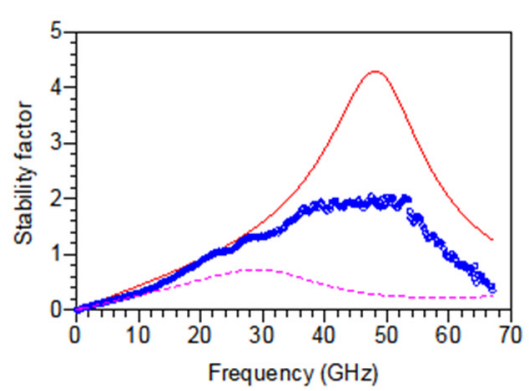

(f)

Figure 13. Comparison of (a) S11, (b) S22, (c) S12, (d) S22, (e) MSG/MAG, and (f) stability factor among the measurement (blue circle), the conventional model (pink dashed line), and the proposed model (red line) from 0.2 to $67 \mathrm{GHz}$ under $\mathrm{V}_{\mathrm{ds}}=16 \mathrm{~V}, \mathrm{~V}_{\mathrm{gs}}=-1.0 \mathrm{~V}$.

As shown in Figures 11-13, the proposed model improves the S12 accuracy due to the modified $C_{d s}$ circuit considering the source via effect. The improved S12 accuracy compared to the previous model allows the proposed small-signal model to predict more similar MSG/MAG and stability factor to measurements at frequencies above $20 \mathrm{GHz}$. Although there is still room for some improvement depending on the bias, it can be seen that the trend is more similar to the measurement than before. It is worth noting that the proposed small-signal model tends to precisely match the measurements, especially near the operating bias of the power amplifier.

\section{Conclusions}

A new $0.15 \mu \mathrm{m}$ GaN HEMT small-signal model for 5G millimeter-wave power amplifier design is proposed considering the source via effect. The proposed model improves the accuracy of S12 by including the parasitic inductance due to coupling between the drain and source via structures at frequencies above millimeter-wave. This improvement contributes to more accurate MSG/MAG and stability factor up to millimeter-wave frequencies. The proposed small-signal model can be applied to GaN HEMTs with other similar source via structures such as an outside source via (OSV) type. In addition, it is expected to contribute to more accurate performance prediction when designing a $5 \mathrm{G}$ millimeter-wave power amplifier by applying it to a large-signal GaN HEMT model.

Funding: This work was supported by the research grant of Pai Chai University in 2020.

Institutional Review Board Statement: Not applicable.

Informed Consent Statement: Not applicable. 


\begin{abstract}
Acknowledgments: This work was supported by the research grant of Pai Chai University in 2020. I would like to express my gratitude to Electronic Device Solution Inc. for the industry-university connection with this research. I would like to thank Win Semiconductors, a foundry company in Taiwan for providing the $0.15 \mu \mathrm{m}$ GaN HEMT samples. I also would like to express my gratitude to Seoul National University Professor Jungsuek Oh and student Seongwoog Oh for their assistance with the measurement equipment.
\end{abstract}

Conflicts of Interest: The author declares no conflict of interest.

\title{
References
}

1. Mishra, U.K.; Parikh, P.; Wu, Y.-F. AlGaN/GaN HEMTs-an overview of device operation and applications. Proc. IEEE 2002, 90, 1022-1031. [CrossRef]

2. Pengelly, R.S.; Wood, S.M.; Milligan, J.W.; Sheppard, S.T.; Pribble, W.L. A Review of GaN on SiC High Electron-Mobility Power Transistors and MMICs. IEEE Trans. Microw. Theory Tech. 2012, 60, 1764-1783. [CrossRef]

3. Kim, J.; Kwon, Y. A high-performance GaN-modified nonuniform distributed power amplifier. IEEE Trans. Microw. Theory Tech 2020, 68, 1729-1740. [CrossRef]

4. Kim, J.; Park, H.; Lee, S.; Kim, J.; Lee, W.; Lee, C.; Kwon, Y. 6-18 GHz, 26-W GaN HEMT compact power-combined non-uniform distributed amplifier. Electron. Lett. 2016, 52, 2040-2042. [CrossRef]

5. Nam, H.; Kim, T.; Sim, T.; Bae, S.; Kim, J. A 2.4 GHz 20 W 8-Channel RF Source Module with Improved Channel Output Balance. Appl. Sci. 2021, 11, 7491. [CrossRef]

6. Ćwikliński, M.; Brückner, P.; Leone, S.; Friesicke, C.; Maßler, H.; Lozar, R.; Wagner, S.; Quay, R.; Ambacher, O. D-Band and G-Band High-Performance GaN Power Amplifier MMICs. IEEE Trans. Microw. Theory Tech. 2019, 67, 5080-5089. [CrossRef]

7. Cwiklinski, M.; Bruckner, P.; Leone, S.; Krause, S.; Friesicke, C.; Massler, H.; Quay, R.; Ambacher, O. First Demonstration of G-Band Broadband GaN Power Amplifier MMICs Operating Beyond $200 \mathrm{GHz}$. In Proceedings of the 2020 IEEE/MTT-S International Microwave Symposium (IMS), Los Angeles, CA, USA, 4-6 August 2020; pp. 1117-1120. [CrossRef]

8. Valletta, A.; Mussi, V.; Rapisarda, M.; Lucibello, A.; Natali, M.; Peroni, M.; Lanzieri, C.; Fortunato, G.; Mariucci, L. Hybrid Electrothermal Simulations of GaN HEMT Devices Based on Self-Heating Free Virtual Electrical Characteristics. IEEE Trans. Electron Devices 2021, 68, 3740-3747. [CrossRef]

9. Chvala, A.; Donoval, D.; Satka, A.; Molnar, M.; Marek, J.; Pribytny, P. Advanced Methodology for Fast 3-D TCAD Device/Circuit Electrothermal Simulation and Analysis of Power HEMTs. IEEE Trans. Electron Devices 2015, 62, 828-834. [CrossRef]

10. Bernardoni, M.; Delmonte, N.; Sozzi, G.; Menozzi, R. Large-signal GaN HEMT electro-thermal model with 3D dynamic description of self-heating. In Proceedings of the European Solid-State Device Research Conference (ESSDERC), Helsinki, Finland, 12-16 September 2011; pp. 171-174. [CrossRef]

11. Kuball, M.; Hayes, J.; Uren, M.; Martin, I.; Birbeck, J.; Balmer, R.; Hughes, B. Measurement of temperature in active high-power $\mathrm{AlGaN} / \mathrm{GaN}$ HFETs using Raman spectroscopy. IEEE Electron Device Lett. 2002, 23, 7-9. [CrossRef]

12. Moron, J.; Leblanc, R.; Lecourt, F.; Frijlink, P. 12W, 30\% PAE, 40 GHz power amplifier MMIC using a commercially available GaN/Si process. In Proceedings of the 2018 IEEE/MTT-S International Microwave Symposium-IMS, Philadelphia, PA, USA, 10-15 June 2018; pp. 1457-1460. [CrossRef]

13. Camarchia, V.; Quaglia, R.; Piacibello, A.; Nguyen, D.P.; Wang, H.; Pham, A.-V. A Review of Technologies and Design Techniques of Millimeter-Wave Power Amplifiers. IEEE Trans. Microw. Theory Tech. 2020, 68, 2957-2983. [CrossRef]

14. Schellnberg, J. Millimeter-Wave GaN SSPAs: Technology to Power 5G and the Future. In Proceedings of the 2020 IEEE BiCMOS and Compound Semiconductor Integrated Circuits and Technology Symposium (BCICTS), Monterey, CA, USA, 16-19 November 2020; pp. 1-7. [CrossRef]

15. Neininger, P.; John, L.; Thome, F.; Friesicke, C.; Brückner, P.; Quay, R.; Zwick, T. Limitations and Implementation Strategies of Interstage Matching in a 6-W, 28-38-GHz GaN Power Amplifier MMIC. IEEE Trans. Microw. Theory Tech. 2021, 69, 2541-2553. [CrossRef]

16. Kim, J.; Choi, K.; Lee, S.; Park, H.; Kwon, Y. 6-18 GHz Reactive Matched GaN MMIC Power Amplifiers with Distributed L-C Load Matching. J. Electromagn. Eng. Sci. 2016, 16, 44-51. [CrossRef]

17. Jarndal, A.; Kompa, G. A new small-signal modeling approach applied to GaN devices. IEEE Trans. Microw. Theory Tech. 2005, 53, 3440-3448. [CrossRef]

18. Ahsan, S.A.; Ghosh, S.; Khandelwal, S.; Chauhan, Y.S. Physics-Based Multi-Bias RF Large-Signal GaN HEMT Modeling and Parameter Extraction Flow. IEEE J. Electron Devices Soc. 2017, 5, 310-319. [CrossRef]

19. Lu, J.; Wang, Y.; Ma, L.; Yu, Z. A new small-signal modeling and extraction method in AlGaN/GaN HEMTs. Solid-State Electron. 2008, 52, 115-120. [CrossRef]

20. Zhao, Z.; Lu, Y.; Yi, C.; Chen, Y.; Cai, X.; Zhang, Y.; Duan, X.; Ma, X.; Hao, Y. A fast small signal modeling method for GaN HEMTs. Solid-State Electron. 2020, 175, 107946. [CrossRef]

21. Schwantuschke, D.; Seelmann-Eggebert, M.; Brückner, P.; Quay, R.; Mikulla, M.; Ambacher, O.; Kallfass, I. A fully scalable compact small-signal modeling approach for $100 \mathrm{~nm}$ AlGaN/GaN HEMTs. In Proceedings of the 2013 European Microwave Integrated Circuit Conference, Nuremberg, Germany, 6-8 October 2013; pp. 284-287.

22. Chen, Y.; Xu, Y.; Wang, F.; Wang, C.; Wu, Q.; Qiao, S.; Yan, B.; Xu, R. A scalable and multi-bias parameter extraction method for a small-signal GaN HEMT model. Int. J. Numer. Model. 2018, 31, 2347. [CrossRef] 
23. Guidry, M.; Wienecke, S.; Romanczyk, B.; Li, H.; Zheng, X.; Ahmadi, E.; Hestroffer, K.; Keller, S.; Mishra, U.K. Small-signal model extraction of mm-wave N-polar GaN MISHEMT exhibiting record performance: Analysis of gain and validation by $94 \mathrm{GHz}$ loadpull. In Proceedings of the 2016 IEEE MTT-S International Microwave Symposium (IMS), San Francisco, CA, USA, 22-27 May 2016; pp. 1-4. [CrossRef]

24. Zhu, G.; Chang, C.; Xu, Y.; Al-Saman, A.A.; Lin, F. A Small-Signal Model Extraction and Optimization Method for AlGaN/GaN HEMT Up to $110 \mathrm{GHz}$. In Proceedings of the 2019 IEEE International Conference on Integrated Circuits, Technologies and Applications (ICTA), Chengdu, China, 13-15 November 2019. [CrossRef]

25. Zhu, G.; Chang, C.; Xu, Y.; Zhang, Z.; Al-Saman, A.A.; Lin, F. A millimeter-wave scalable small-signal modeling approach based on FW-EM for AlGaN/GaN HEMT up to $110 \mathrm{GHz}$. Microw. Opt. Technol. Lett. 2021, 63, 2145-2152. [CrossRef]

26. Mußer, M.; Raay, F.V.; Brückner, P.; Bronner, W.; Quay, R.; Mikulla, M.; Ambacher, O. Individual source vias for GaN HEMT power bars. In Proceedings of the 2013 European Microwave Integrated Circuit Conference, Nuremberg, Germany, 6-8 October 2013; pp. 184-187.

27. Dambrine, G.; Cappy, A.; Heliodore, F.; Playez, E. A new method for determining the FET small-signal equivalent circuit. IEEE Trans. Microw. Theory Tech. 1988, 36, 1151-1159. [CrossRef]

28. Yanagawa, S.; Ishihara, H.; Ohtomo, M. Analytical Method for Determining Equivalent Circuit Parameters of GaAs FET's. IEEE Trans. Microw. Theory Tech. 1996, 44, 1637-1641. [CrossRef]

29. Lee, D.H. The Analytic Small-Signal Equivalent Parameter Extraction Method of HEMT and Its Application to Noise Modeling. Master's Thesis, Seoul National University, Seoul, Korea, 1999.

30. Gonzales, G. Microwave Transistor Amplifiers, 2nd ed.; Prentice-Hall: Hoboken, NJ, USA, 1997. 